\title{
THE IMPACT OF AESTHETIC GYNAECOLOGY PROCEDURES ON FEMALE PATIENTS' SEXUALITY
}

\author{
Angelika Iwaszko ${ }^{A, B, C}$, Justyna Kamińska ${ }^{D, E, F}$, Anna Szablewska ${ }^{D}$
}

Faculty of Health Sciences with the Institute of Maritime and Tropical Medicine, Institute of Nursing and Midwifery, Department of Obstetric and Gynaecological Nursing, Medical University of Gdańsk, Poland

\section{Authors' contribution:}

A. Study design/planning • B. Data collection/entry • C. Data analysis/statistics $\bullet$ D. Data interpretation $\bullet$ E. Preparation of manuscript $\bullet$ F. Literature analysis/search $\bullet$ G. Funds collection

\author{
Address for correspondence: \\ mgr Anna Szablewska \\ Faculty of Health Sciences with the Institute \\ of Maritime and Tropical Medicine, \\ Institute of Nursing and Midwifery, \\ Department of Obstetric and Gynaecological \\ Nursing, Medical University of Gdańsk \\ Gdańsk, Poland \\ e-mail: abazychowska@gumed.edu.pl \\ SUBMITTED: 28.11.2021 \\ ACCEPTED: 28.12.2021 \\ DOl: https://doi.org/10.5114/ppiel.2021.113785
}

\begin{abstract}
Aim of the study: To recognize the impact of aesthetic gynaecology treatments on women's sexual life. Material and methods: The research was carried out in private gynaecological offices. The research material consisted of a group of 97 patients. The study uses a method of a diagnostic survey with the use of a research tool of our own authorship and questions characterizing the demographic and social data of the respondents. The survey questionnaire consisted of 20 closed questions with the possibility of single or multiple choice.

Results: The analysis showed a relationship between the performed procedure and the impact on sexual satisfaction and female self-esteem $(p<0.05)$ : the procedure significantly influenced sexual satisfaction in $69 \%$ of women and self-esteem in $76 \%$ of women. The main factors influencing the decision about undergoing plastic surgery were decreased self-esteem in $41 \%$, no sexual satisfaction during sexual intercourse in $32 \%$, and ailments related to relaxation of the vagina in $27 \%$.

Conclusions: Aesthetic gynaecology significantly affects the quality of women's sexual life. The main factors influencing a woman's decision to undergo an aesthetic treatment are reduced self-esteem, lack of sexual satisfaction, ailments related to vaginal relaxation, and urinary incontinence. The aesthetic procedure performed increases the woman's self-esteem, the frequency of her sexual activity, and the possibility of achieving orgasm. Women who have decided to undergo a procedure in the field of aesthetic gynaecology can accept the higher costs of this procedure. Key words: sexuality, aesthetic gynaecology, plastic gynaecology, quality of sexual life.
\end{abstract}

\section{INTRODUCTION}

Aesthetic gynaecology is currently one of the most dynamically developing areas of gynaecology. It is defined as a set of procedures aimed at eliminating the mental and health consequences resulting from defects of the genital organs, improving the appearance and attractiveness of the external genital organs, and improving their sexual functions. All these activities lead to the improvement of the quality of life, increased self-esteem, and woman's sexual satisfaction [1]. Sexual satisfaction is an essential component of human sexuality, which is considered to be the main component of quality of life, sense of physical and mental health, as well as the quality of relationships. A satisfying sexual life has a positive effect on the relationship and strengthens it in many dimensions [2]. The most common problems in plas- tic gynaecology include enlarged labia, loose vagina syndrome, wide vaginal opening syndrome, and vaginal and labial atrophy. Defects in the intimate area caused by labour, menopause, congenital malformations, or other external factors may have a negative impact on a woman's life.

\section{AIM OF THE STUDY}

The main aim of the study was to find the influence of aesthetic gynaecology on female sexuality. It takes into account whether the study increased sexual satisfaction in a woman and her partner, the main factors influencing the decision to undergo the procedure, and the role played by the cost of the procedure had. It was also important that the effect was satisfactory and increased self-esteem. Also, the aim was to assess the relationship between age, place of 
residence, and the number of births in the group of women who decide to undergo the procedure in the field of aesthetic gynaecology.

\section{MATERIAL AND METHODS}

The research was carried out in private gynaecological offices in the first quarter of 2020. The research material consisted of a group of 97 patients.

The study used the method of a diagnostic survey with the use of a research tool of our own authorship and questions characterizing the demographic and social data of the respondents. The survey questionnaire consisted of 20 closed questions with the possibility of single and multiple choice. All statistical calculations were performed using the IBM SPSS 23 statistical package and the Excel 2013 spreadsheet. In the calculations, $p<0.05$ was assumed as the significance level.

Table 1. The main characteristics of the group

\begin{tabular}{|c|c|c|}
\hline Characteristics & No. & $\%$ \\
\hline Respondents & 97 & 100 \\
\hline \multicolumn{3}{|l|}{ Age (years) } \\
\hline$<25$ & 39 & 40.2 \\
\hline $26-35$ & 36 & 37.1 \\
\hline $36-45$ & 12 & 12.4 \\
\hline $46-55$ & 6 & 6.2 \\
\hline$>55$ & 4 & 4.1 \\
\hline \multicolumn{3}{|l|}{ Education level } \\
\hline Basic education & 1 & 1.0 \\
\hline Secondary education & 30 & 30.9 \\
\hline $\begin{array}{l}\text { Higher education (Bachelor's/ } \\
\text { Master's degree) }\end{array}$ & 62 & 63.9 \\
\hline Vocational education & 4 & 4.1 \\
\hline \multicolumn{3}{|l|}{ Place of residence } \\
\hline Village & 9 & 9.3 \\
\hline City $<25,000$ inhabitants & 5 & 5.2 \\
\hline City $<50,000$ inhabitants & 16 & 16.5 \\
\hline City $<100,000$ inhabitants & 23 & 23.7 \\
\hline City $<150,000$ inhabitants & 44 & 45.3 \\
\hline \multicolumn{3}{|l|}{ Marital status } \\
\hline Single & 38 & 39.2 \\
\hline Marriage & 33 & 34.0 \\
\hline Widow & 3 & 3.1 \\
\hline Divorced & 5 & 5.2 \\
\hline Informal partner & 18 & 18.6 \\
\hline \multicolumn{3}{|l|}{ Financial situation } \\
\hline Very good & 30 & 29.9 \\
\hline Good & 47 & 48.5 \\
\hline Adequate & 18 & 18.6 \\
\hline Bad & 2 & 2.1 \\
\hline
\end{tabular}

\section{RESULTS}

\section{Group characteristics}

The study included patients from private gynaecological offices aged from less than 35 years (40.2\%) to more than 55 years (4.1\%). Women aged $26-35$ years accounted for $37.1 \%$ of the respondents, patients aged $36-45$ years $12.4 \%$, and aged $46-55$ years $6.2 \%$ of the respondents. Most of the respondents (63.9\%) declared having a bachelor's or master's degree. Secondary education was indicated by $30.9 \%$ of the respondents, vocational by $4.1 \%$, and the least of the respondents had primary education (1.0\%). The procedures in the field of aesthetic gynaecology were most often used by single women (39.2\%) and then by married women (34.9\%). Widows and divorced women used plastic gynaecology procedures in 3.1\% and $5.2 \%$, respectively. Patients who lived in a nonlegalized relationship benefited from aesthetic gynaecology procedures in $18.6 \%$ of cases. Almost half of the respondents (48.5\%) declared a good financial situation. A very good situation was declared by $29.9 \%$ of the respondents, a sufficient situation by $18.6 \%$, and a bad financial situation was declared by $2.1 \%$ of the respondents. Nearly half of the respondents (46.4\%) were nulliparous women. $27.8 \%$ of the respondents were people who had given birth twice, $15.5 \%$ of the respondents had given birth once, and $10.3 \%$ of women had given birth 3 or more times. Of the respondents, $39.3 \%$ had had a vaginal delivery, $7.0 \%$ of the respondents had had a caesarean section, and $5.2 \%$ of the respondents had completed the delivery naturally and surgically. Almost half of the respondents (45.8\%) had never given birth (Table 1 ).

The analysis found a significant but weak relationship between age and undergoing procedures in the field of aesthetic gynaecology. Older women more frequently underwent this procedure. In particular, among examined patients in the 36-45 and 46-55 age groups, all women underwent aesthetic gynaecology, which could be a result of the small size of these groups (Table 2).

The average number of procedures in the study group in the field of aesthetic gynaecology across age ranges is presented in Figure 1. The highest number of procedures were performed in the age group of 36-45 years (more than 3 procedures on average), followed by the age group $46-55$ years (1.5 procedures on average). In all other groups this statistic was estimated as being equal to about 1 .

The most frequently performed procedures were: $23 \%$ - vaginoplasty, $8 \%$ - laser treatment of urinary incontinence, $13 \%$ - filling of the labia, and G-spot with hyaluronic acid. Perineoplasty is used by $10 \%$ of respondents (Fig. 2).

The analysis showed a relationship between the procedure performed and the impact on sexual sat- 
Table 2. Dependence between age and undergoing procedures - Cramer's test

\begin{tabular}{|c|c|c|c|c|c|c|}
\hline \multirow[t]{2}{*}{ Age (years) } & \multicolumn{2}{|c|}{ Undergoing procedures } & \multirow[t]{2}{*}{$\chi^{2}$ test } & \multirow{2}{*}{$\begin{array}{c}\text { Cramer's V contingency } \\
\text { coefficient }\end{array}$} & \multirow[t]{2}{*}{$d f$} & \multirow[t]{2}{*}{$P$-value } \\
\hline & No (\%) & Yes (\%) & & & & \\
\hline$<25$ & 41.0 & 59.0 & 10.3 & 0.15 & 4 & 0.03 \\
\hline $26-35$ & 33.3 & 66.7 & & & & \\
\hline $36-45$ & 0.0 & 100.0 & & & & \\
\hline $46-55$ & 0.0 & 100.0 & & & & \\
\hline$>55$ & 25.0 & 75.0 & & & & \\
\hline
\end{tabular}

isfaction and female self-esteem $(p<0.05)$ : the procedure significantly improved sexual satisfaction in $69 \%$ of women, and self-esteem in $76 \%$ of women. The data revealed that the main factors influencing the decision about undergoing plastic surgery were in $41 \%$ - decreased self-esteem, in $32 \%$ - no sexual satisfaction during sexual intercourse, and in $27 \%-$ ailments related to relaxation of the vagina.

The analysis showed that after the procedure the frequency of sexual intercourse increased in $65 \%$ of the surveyed women who underwent the procedure, $12 \%$ had no opinion, and $20 \%$ believed that nothing had changed. The analysis found that after the procedure the frequency of achieved orgasms increased in $53 \%$ of the surveyed women who underwent the procedure, $25 \%$ had no opinion, and $20 \%$ believed that nothing had changed.

The data showed also that the type of labour was important: aesthetic procedures were more often chosen by women after natural births - 52.9\%,

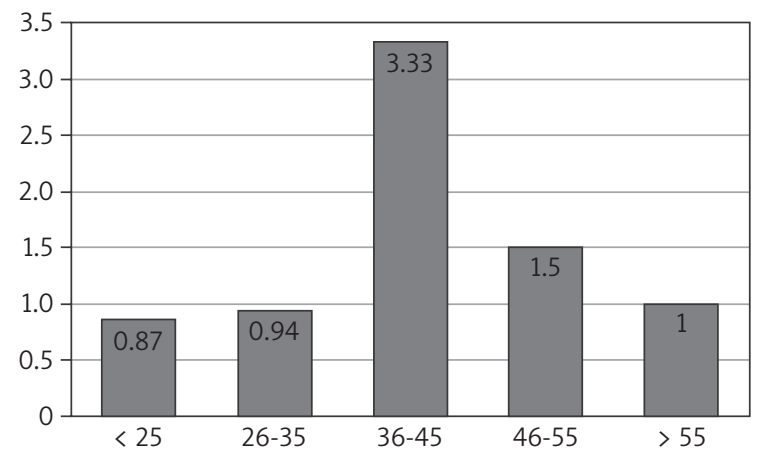

Figure 1. Average number of procedures and age ranges

after caesarean sections it was $10.3 \%$, and $36.2 \%$ of respondents were not questioned.

The analysis revealed that women who decided to undergo a procedure in the field of aesthetic gynaecology were able to accept the higher costs of this treatment. The data are presented in Table 3 (Fig. 3).

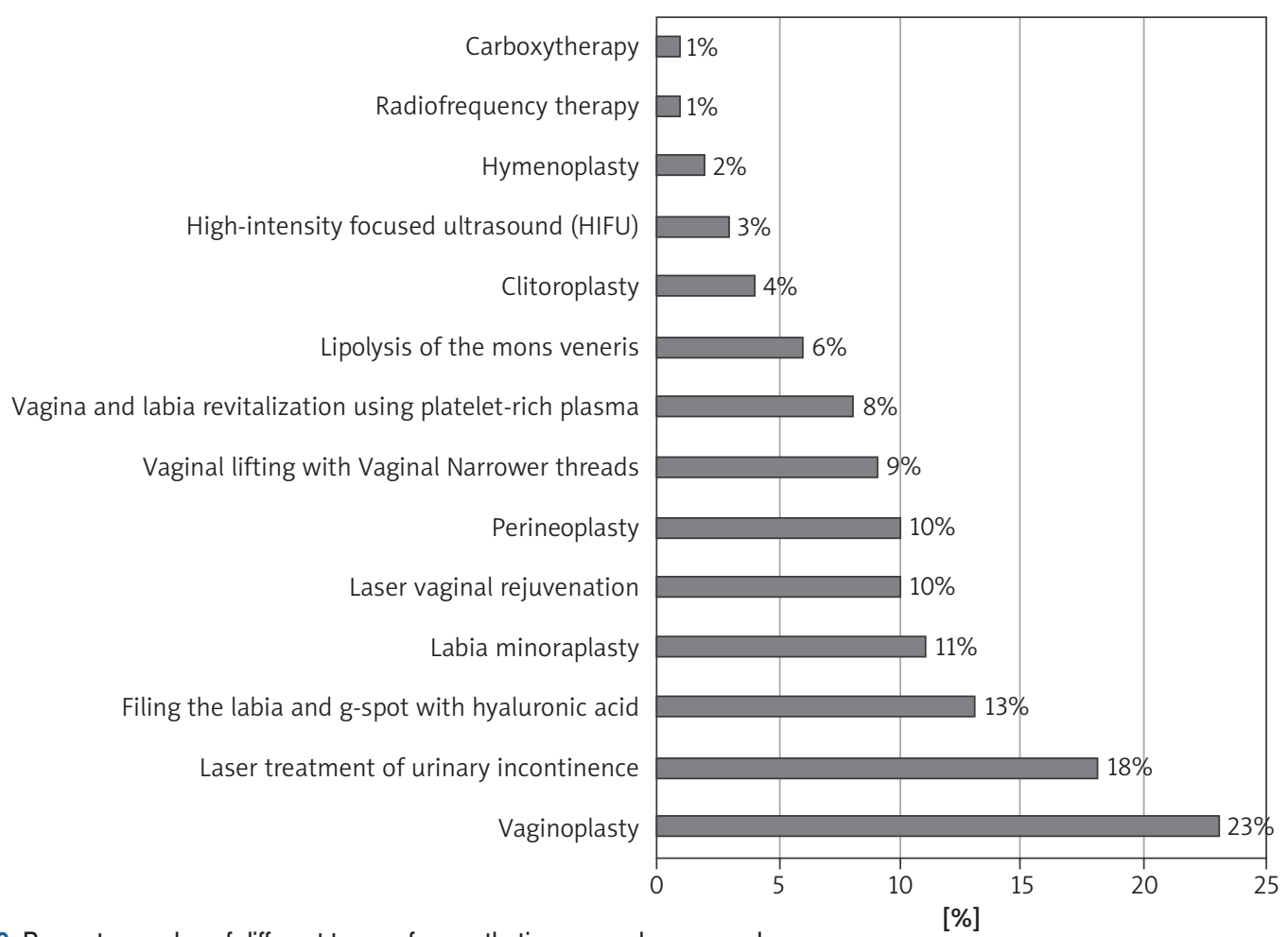

Figure 2. Percentage value of different types of anaesthetic gynaecology procedures 
Table 3. Correlation between the accepted cost of procedures and undergoing the procedure

\begin{tabular}{|c|c|c|c|c|c|c|}
\hline \multirow{2}{*}{$\begin{array}{l}\text { Cost of procedure } \\
\text { (PLN) }\end{array}$} & \multicolumn{2}{|c|}{ Undergoing procedures } & \multirow[t]{2}{*}{$\chi^{2}$ test } & \multirow{2}{*}{$\begin{array}{c}\text { Cramer's V contingency } \\
\text { coefficient }\end{array}$} & \multirow[t]{2}{*}{$d f$} & \multirow[t]{2}{*}{$P$-value } \\
\hline & No (\%) & Yes (\%) & & & & \\
\hline $300-1000$ & 20.8 & 8.8 & 26.5 & 0.52 & 5 & 0.00 \\
\hline $1100-2000$ & 37.5 & 10.3 & & & & \\
\hline $2100-3000$ & 12.5 & 26.5 & & & & \\
\hline $3100-4000$ & 20.8 & 20.6 & & & & \\
\hline$>4100$ & 8.3 & 33.8 & & & & \\
\hline
\end{tabular}

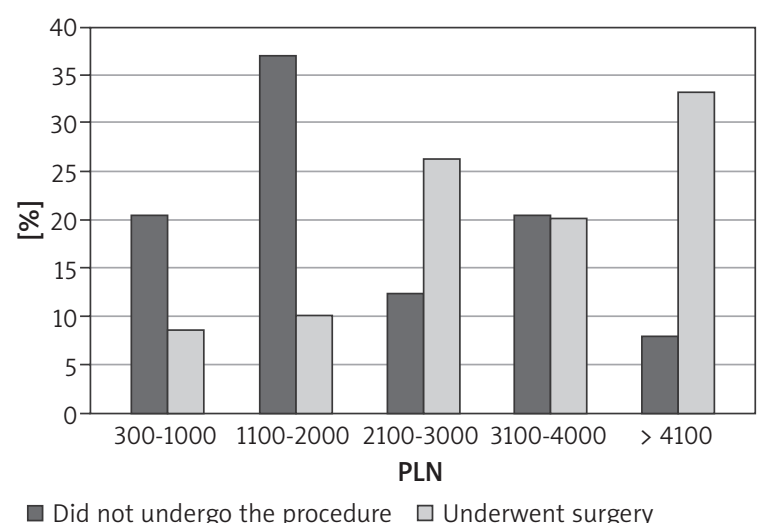

Figure 3. Accepted cost of procedure

\section{DISCUSSION}

Aesthetic gynaecology is currently one of the most dynamically developing fields of aesthetic medicine. The number of patients who decide to undergo treatments in the field of aesthetic gynaecology is constantly increasing, and access to treatments individually tailored to the patient's needs seems to be getting easier. Contemporary women more and more boldly use the benefits of plastic gynaecology because, for the majority of them, it may turn out to be the only chance to improve psychological comfort, increase the sense of one's sexuality and attractiveness, as well as restore the correct anatomy of the genital organs, which could influence everyday functioning. Along with the development of the field of aesthetic gynaecology and the growing popularity of treatments among women, more and more studies in this field are also being published. Research by Salgado et al. [3] showed that aesthetic gynaecology is a rapidly developing and influential field regarding mental and physical functioning and satisfaction with sexual life. According to the cited studies, the largest group of patients were women aged $30-40$ years $(47.3 \%)$ and the smallest group comprised those $>60$ years of age (14.6\%), and the most common procedures were labiaplasty $(17 \%)$, hymenoplasty (14\%), clitoroplasty (16\%), vaginoperineoplasty (30\%), and filling the G-spot with hyaluronic acid (23\%) [3]. Similar results were obtained in a study conducted by Goodman on a group of 258 women, of whom 153 underwent labiaplasty, 24 clitoroplasty, 47 vaginoperineoplasty, and 34 combined operations, i.e. a combination of labiaplasty/clitoroplasty with simultaneous vaginoplasty. As many as $91.6 \%$ of patients after surgery reported satisfaction from the obtained aesthetic and functional effects, as well as improvement of the quality of sexual intercourse, compared to the time before the procedure [4]. In the authors' research, the largest group of respondents were women aged $<25$ years $(40.2 \%)$ and $26-35$ years $(37.1 \%)$, and the smallest group were $>55$ years of age. (4.1\%). However, it should be noted that in the group < 25 years old $59 \%$ of women underwent aesthetic gynaecological surgery, and in the group 36-45 years old as many as $100 \%$ of women underwent at least one surgery. Based on our research, the most frequently performed procedures in the field of aesthetic gynaecology include vaginoplasty (23\%), laser treatment of urinary incontinence (18\%), filling the labia and G-spot with hyaluronic acid (13\%), and perineoplasty (10\%), which largely coincides with the research of the above-mentioned authors. The analysis of our own research also showed that the treatments had a positive effect on sexual satisfaction in $69.1 \%$ and increased self-esteem in $76.5 \%$ of respondents. The assessment of sexual function in women after gynaecological procedures was also carried out by Lalos et al. [5], who proved that $79 \%$ of the examined women during long-term follow-up after gynaecological procedures remained sexually active and expressed satisfaction from intimate life [5]. An important role in the assessment of the impact of aesthetic gynaecology on the quality of sexual life was presented in the studies conducted by Millheiser et al. [6, 7], which included 421 patients with vaginal relaxation syndrome as a consequence of vaginal delivery. The relaxation of vaginal tissues and thus the reduction of sensitivity to sexual stimuli was a more significant problem for women than urinary incontinence or weight gain $[6,7]$. According to studies conducted by Pauls et al. [8], a decrease in the quality of sexual life, including the frequency of sexual contact and the feeling of satisfaction by a woman and her partner, was the most important problem among female patients. These studies have shown that the problem affects $43-88 \%$ of women who have under- 
gone at least one childbirth by natural means. These patients reported a decrease in vaginal tension and a reduction in sexual stimuli, which translated into a lack of satisfaction in both partners, difficulties in achieving orgasm, and decreased self-esteem [8]. According to our research, more often women undergo aesthetic gynaecology after childbirth by natural means $(52.9 \%)$ than those after caesarean section (10.3\%), and the rest are women who were prompted by anatomical defects or purely aesthetic reasons (36.8\%). A woman's lack of sexual satisfaction during sexual intercourse (32\%) and decreased self-esteem $(41 \%)$ was more common among respondents who gave birth naturally than those who did not give birth at all or gave birth by caesarean section. In the case of $27 \%$ of the respondents, complaints related to vaginal relaxation postpartum or the occurrence of an episiotomy scar (15\%) were also important factors influencing the decision to undergo aesthetic surgery. In contrast, studies by Fehniger et al. [9] did not show any significant influence of the previous deliveries on the patient's sexual functions or her perception of sexual satisfaction, and thus were not factors influencing the decision to perform the procedure [9]. On the other hand, Dobbeleir et al. in independent studies showed that women who had undergone vaginal delivery comprised the largest group of patients suffering from vaginal relaxation syndrome (76\%) $[10,11]$. Extensive research by Goodman et al. [12] also showed a correlation between vaginal relaxation and decreased sexual satisfaction in women (52.1\%) and their partners (47.3\%). The performed vaginoplasty had a positive effect on sexual satisfaction in $70 \%$ of the surveyed women, and it also improved the quality of sexual intercourse according to their partners (47.6\%) [12]. Our own research revealed similar dependencies. An effective procedure in the field of aesthetic gynaecology increased the sexual frequency in $64.7 \%$ of the respondents, thus affecting the frequency of achieving orgasm in $52.9 \%$ and increasing the partner's sexual satisfaction during sexual intercourse (60.3\%).

In the publication of Drews et al. [13] nearly half of the respondents reported discomfort in the vaginal area, but only $30 \%$ of them reported the problem to a doctor. The examined women were in postmenopausal age, and their main ailments were related to atrophic changes in the vagina and vulva, decreased elasticity of the vaginal walls, and a feeling of itching and burning. The decision to perform the procedure in the field of aesthetic gynaecology was determined mainly by vaginal atrophy (76\%), which resulted in pain and discomfort during sexual intercourse, difficulties in obtaining lubrication, and decreased self-esteem [13]. According to the authors' research, postmenopausal women accounted for $4.1 \%$ of the respondents, out of which $75 \%$ underwent at least one plastic surgery. The decision to perform the procedure was determined mainly by discomfort and pain during sexual intercourse (12\%), laxity of the skin around the labia (13\%), and urinary incontinence (33\%). Patients who participated in the own study were asked how much of an impact decision making for the procedure in the field of aesthetic gynaecology, had self-esteem and undergoes the procedure at the partner's request. Lower self-esteem was reported by $41 \%$ of the respondents, while $7 \%$ of the women underwent the procedure at their partner's request. Such a large percentage of women with low self-esteem may be influenced by the idealized image of women in society, which was also shown in the research by Colson. In them, he mentions a doctor from the USA who presented his patients with photos from erotic magazines to help them choose the appearance of their genitals in line with their idea of the perfect image. The above-mentioned studies also presented that women can incur high costs in their quest to obtain the dream body image [14]. According to our research, women who have decided to undergo a procedure in the field of aesthetic gynaecology can accept higher costs of the procedure to obtain satisfaction and improve the quality of their sex life. However, it should be mentioned that most of the respondents were people declaring a very good or good financial situation, which could have a significant influence on making the decision about the procedure, despite its high cost. The increase in women's awareness of the self-creation of their bodies means that aesthetic gynaecology is one of the most dynamically developing branches of gynaecology. Thanks to the availability of many treatments, it is possible to eliminate or minimize aesthetic and functional defects. Recent publications and research suggest that treatments in the field of aesthetic gynaecology are safe and effective, and their impact on the quality of women's sexual life and self-esteem is significant. The constantly increasing percentage of women looking for a solution to their problems in this type of surgery has caused rapid development of this field, the emergence of new methods of treatment, and allows for numerous studies, thanks to which it is possible to learn about the correlation between aesthetic surgery and sexology. For some women, deciding to perform an aesthetic gynaecology procedure may turn out to be the only chance to achieve full sexual satisfaction and improve their quality of life.

\section{CONCLUSIONS}

Aesthetic gynaecology significantly affects the quality of women's sexual life.

The aesthetic gynaecology treatments are performed by women mainly between 36 and 55 years of age, of whom most are women who have undergone 
childbirth by natural means, rather than those who gave birth by caesarean section or did not give birth.

The main factors influencing a woman's decision to undergo an aesthetic treatment are as follows: reduced self-esteem, low level of sexual satisfaction during sexual intercourse, ailments related to vaginal relaxation, and urinary incontinence.

The performed aesthetic procedure increases the woman's self-esteem, and increases the frequency of her sexual activity and the possibility of achieving orgasm during sexual intercourse.

Women who have decided to undergo the procedure in the field of aesthetic gynaecology can accept the higher costs of this procedure.

\section{Disclosure}

The authors declare no conflict of interest.

\section{References}

1. Barwijuk A. Atlas ginekologii plastycznej. Wydawnictwo Lekarskie PZWL, Warszawa 2016.

2. Dundon CM, Rellini AH. More than sexual function: Predictors of sexual satisfaction in a sample of women age 40-70. J Sex Med 2010; 7: 896-904.

3. Salgado J, Stan MD, Monstrey SJ, et al. Aesthetic surgery of the female genitalia. Semin Plast Surg 2011; 25: 130-141.

4. Goodman MP. Female cosmetic genital surgery. Obstet Gynecol 2009; 113: 154-159.

5. Lalos O, Berglund AL. Impact of urinary and climacteric symptoms on social and sexual life after surgical treatment of stress urinary incontinence in women: a long-term outcome. J Adv Nurs 2001; 33: 326-327.

6. Millheiser LS, Kingsberg SA, Chen BH, et al. Cross-sectional survey of sexual health and vaginal laxity following vaginal delivery. J Sex Med 2010; 7: 239.

7. Millheiser LS, Kingsberg S, Pauls RN. A cross-sectional survey to assess prevalence and symptoms associated with laxity of the vaginal introitus. Int Urogynecol J 2010; 21: 298-299.

8. Pauls RN, Fellner AN, Davila GW. Vaginal laxity; a poorly understood quality of life problem. Survey of physician members of the International Urogynecological Association (IUGA). Int Urogynecol J 2012; 23: 1435-1448.

9. Fehniger JE, Brown JS, Creasman JM. Childbirth and female sexual function later in life. Obstet Gynecol 2013; 122: 988997.

10.Dobbeleir JM, Landuyt KV, Monstrey SJ, et al. Aesthetic surgery of the female genitalia. Semin Plast Surg 2011; 25: 130-141.

11. Adamo C, Corvi M. Cosmetic mucosal vaginal tightening (lateral colporrhaphy): improving sexual sensitivity in women with a sensation of wide vagina. Plast Reconstr Surg 2009; 123: 212-213.

12. Goodman MP, Placik OJ, Benson RH, et al. A large multicenter outcome study of female genital plastic surgery. J Sex Med 2010; 7 (4 Pt 1): 1565-1577.

13. Drews K, Pieńkowski W, Perlik M. Atrofia pochwy - diagnostyka i leczenie. Przegląd Menopauzalny 2005; 5: 16-23.

14. Colson MH. Female cosmetic genital surgery: point-counterpoint. Gynecol Obstet Fertil 2012; 40: 445-448. 